\title{
AVIFAUNA COLIDIDA EM ESTRUTURAS DE VIDRO NO PERÍMETRO URBANO DO BALNEÁRIO RINCÃO, SANTA CATARINA
}

\section{AVIFAUNA COLLISION ON GLASS FRONTS OF A URBAN AREA IN BALNEÁRIO RINCÃO, SANTA CATARINA}

\author{
Aline da Silva Stolk ${ }^{1}$ \\ Carina Girelli ${ }^{1}$ \\ Luana Pasini Miguel $^{1}$ \\ Gilca Benedet ${ }^{2}$ \\ Mainara Cascaes ${ }^{3}$
}

\begin{abstract}
RESUMO
As aves são afetadas de diversas formas pelas atividades antrópicas, sendo a destruição dos habitats a principal causadora do desequilíbrio. Um fato pouco conhecido, mas extremamente relevante, é a perda desses indivíduos por colisão em estruturas transparentes oriundas de fachadas, painéis ou muros de vidro. O presente trabalho teve por objetivo verificar a ocorrência de choque mecânico de aves em residências com muros de vidro no município litorâneo de Balneário Rincão, Santa Catarina, de modo a avaliar as condições das ocorrências em relação as características físicas da ave, do muro e do entorno, durante 12 meses de pesquisa. No decorrer do projeto foram amostradas, entre coletas e registros fotográficos, um total de 110 carcaças decorrentes das colisões em estruturas de vidro, distribuídas em 12 espécies e 10 famílias, sendo 21 indivíduos não identificados.
\end{abstract}

PALAVRAS-CHAVE: Aves; Muros de vidro; Mata Atlântica.

\begin{abstract}
The birds are affected in different ways by human activities, and habitat destruction the main cause of theim balance. A little known fact, but extremely important, is the loss of these individuals because collision in transparent structures, specialonglasswalls. This study aims to verify the occurrence of avifauna collisionon glass fronts in homes, at Balneário Rincão, Santa Catarina State, in order to assess the conditions of the occurrences concerning the physical characteristics of the bird, the wall and the surrounding for 12 months of research. During the Project were sampled, between collections and photographic records, a total of 110 carcasses resulting from collisions in glass structures, distributed in 12 species and 10 families, 21 unidentified individuals.
\end{abstract}

KEY WORDS: birds, glasseswall, Atlantic rain forest.

\section{INTRODUÇÃO}

\footnotetext{
${ }^{1}$ Acadêmicas do curso de Engenharia Ambiental da Universidade do Extremo Sul Catarinense - UNESC.

${ }^{2}$ Professora do Curso de Engenharia Ambiental da Universidade do Extremo Sul Catarinense - UNESC.

${ }^{3}$ Professora do Curso de Ciências Biológicas da Universidade do Extremo Sul Catarinense - UNESC, email: mcascaes@unesc.net
} 
O estudo da avifauna é de vital importância para a manutenção e preservação ambiental, pois a observação, monitoramento e compreensão de seus hábitos alimentares e reprodutivos podem ser utilizados como indicador de qualidade ambiental em um determinado local (PRIMACK; RODRIGUES, 2001). Segundo Terra e Constante (2005), as aves desempenham funções ecológicas muito importantes e úteis, tanto no meio rural, quanto no urbano, pois realizam a dispersão de sementes e favorecem a regeneração de florestas, auxiliam a ciclagem de nutrientes, pois aves saprófagas, como urubus, se alimentam de animais em decomposição, contribuem com aspectos de contemplação da paisagem, entre outros.

O Brasil possui 1.872 espécies de aves registradas, até o momento, dentro dos seus limites territoriais, representando 31 ordens e 97 famílias (CBRO, 2014). Esse número de espécies corresponde a aproximadamente $18 \%$ de toda a riqueza de aves do mundo. Muitas das espécies que ocorrem em nosso território são compartilhadas com outros países, mas entre 10 e 15\% delas são endêmicas ao país (VALENTE et al., 2011). A principal ameaça para as aves brasileiras é a perda e degradação do habitat, seguida pela captura excessiva, e outras ameaças incluem a invasão de espécies exóticas e a poluição, a perturbação antrópica e a morte acidental, alterações na dinâmica das espécies nativas, desastres naturais e perseguição (MARINI; GARCIA, 2005).

De acordo com Barros (2010) a segunda maior causa antropológica da mortalidade de pássaros ao redor do mundo, atrás somente da destruição do habitat, é a colisão destes com painéis de vidro transparente e/ou reflexivo, em vidraças de residências e prédios comerciais, tanto em áreas urbanas como nos meios rurais. As colisões ocorrem porque as aves não veem o vidro como uma barreira, principalmente devido ao seu sistema de visão. Enquanto o ser humano tem uma visão tricromática, as aves têm um quarto cone, sensível à radiação ultravioleta (BARROS, 2010). Muitas aves podem ver na faixa ultravioleta, capacitando-as da visão de características ambientais inacessíveis para nós, mas acessíveis aos insetos (tais como "guias de néctar" que refletem o ultravioleta que atraem insetos polinizadores). Muitas espécies de pato, beija-flores, martins-pescadores e passeriformes podem ver próximo ao ultravioleta (UV), abaixo de $370 \mathrm{~nm}$ (HICKMAN et al., 2004). Dessa forma, os reflexos de árvores, água e alimentos tornam confusos nos vidros. 
O mercado de vidros planos no Brasil vem apresentando, nos últimos anos, considerável evolução (MONTANO; BASTOS, 2013). Segundo Bastos (2013), esse crescimento deve-se, não somente por questões estéticas, mais pelas diversas funcionalidades desse material. Além de proporcionar um aspecto mais moderno, o vidro é capaz de gerar conforto térmico e acústico, ao mesmo tempo em que permite a utilização de luz natural nos ambientes. Ainda, tem sido impulsionado pelo crescimento da renda e pela sua melhor distribuição, bem como o aumento da oferta de crédito e de seu acesso pela população brasileira (MONTANO; BASTOS, 2013). Observa-se a regra da oferta e da procura neste setor, devido ao aumento na procura, houve um crescimento na oferta, ou seja, maior concorrência por parte das empresas, assim os preços diminuíram, incentivando ainda mais a utilização do vidro.

Sendo assim, o presente estudo teve por objetivo avaliar a composição da avifauna colidida em estruturas de vidro na área urbana do Balneário Rincão, contabilizando o número de aves mortas, e buscando relacionar o número de colisões com as extensões dos muros de vidro e ambiente de entorno.

\section{MATERIAL E MÉTODOS}

\section{1 Área de estudo}

O presente estudo foi desenvolvido no município de Balneário Rincão, localizado no sul do Estado de Santa Catarina. Este município foi emancipado em 2013 e conta com uma orla marítima de 13 quilômetros, com duas plataformas de pesca e seis lagoas. De acordo com o Instituto Brasileiro de Geografia e Estatística (IBGE), sua população no ano de 2010 era de 10.923 habitantes e conta na alta temporada, com uma população de quase 150 mil pessoas (IBGE, 2010).

Conforme a análise de Sônego (2014, comunicação pessoal), o litoral sul de Santa Catarina apresenta clima quente no verão e ameno no inverno, com chuvas bem distribuídas durante o ano. O clima é subtropical úmido sem estação seca definida e com verão quente (Cfa), pelo sistema de Koeppen. A vegetação característica é de restinga e encontra-se na forma descontínua em uma mescla de espécies nativas e exóticas. 
Revista Tecnologia e Ambiente, v. 21, n.1, 2015, Criciúma, Santa Catarina. ISSN: 1413-8131 (versão impressa) ISSN: 2358-9426 (versão eletrônica)

\subsection{Metodologia}

Para desenvolvimento da pesquisa foram selecionadas e mapeadas com uso de GPS (Garmin) sistema Datum (SIRGAS 2000), 82 residências que apresentavam muros de vidro, compreendidas entre a plataforma Norte e a rodovia de acesso Sul do Balneário Rincão e distribuídas ao longo de 12 quadras na parte interiorana do continente ao longo da área habitada do Balneário (Figura 1).

Figura1 - Mapa da área urbana no município de Balneário Rincão, Santa Catarina, com destaque para as residências amostradas para a pesquisa, indicadas nos pontos em vermelho.

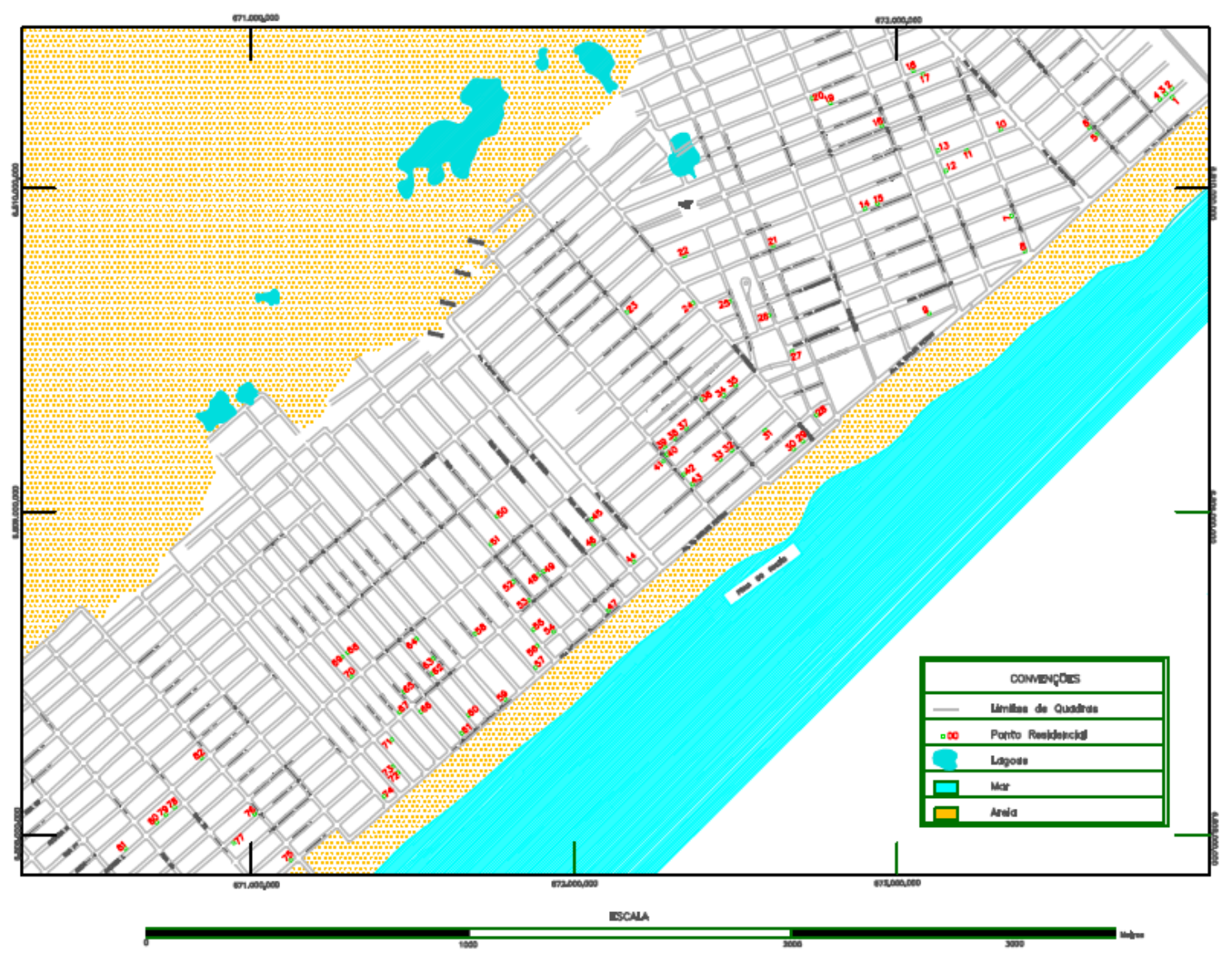

Fonte: Autores. 
As coletas in loco das aves ocorreram quinzenalmente entre os meses de abril de 2013 e março de 2014, a amostragem tinha início às 6 h e era finalizada as 9 h e 30 min, não alternando a rota do observador.

As aves pós-colisões eram amostradas quando encontradas a uma distância de 1,5 m para dentro ou fora do muro de vidro das residências previamente selecionadas. A amostragem consistia no registro fotográfico de todos os indivíduos e na coleta das carcaças ao alcance do pesquisador, que para tal contou com o auxílio de coletor gancho e um puçá (Figura 2).

Figura 2 - Coletor gancho (A) e Puçá (B). Instrumentos utilizados para as coletas das carcaças de aves encontradas nas proximidades dos muros de vidro das casas previamente selecionadas para a pesquisa, no município de Balneário Rincão, Santa Catarina.

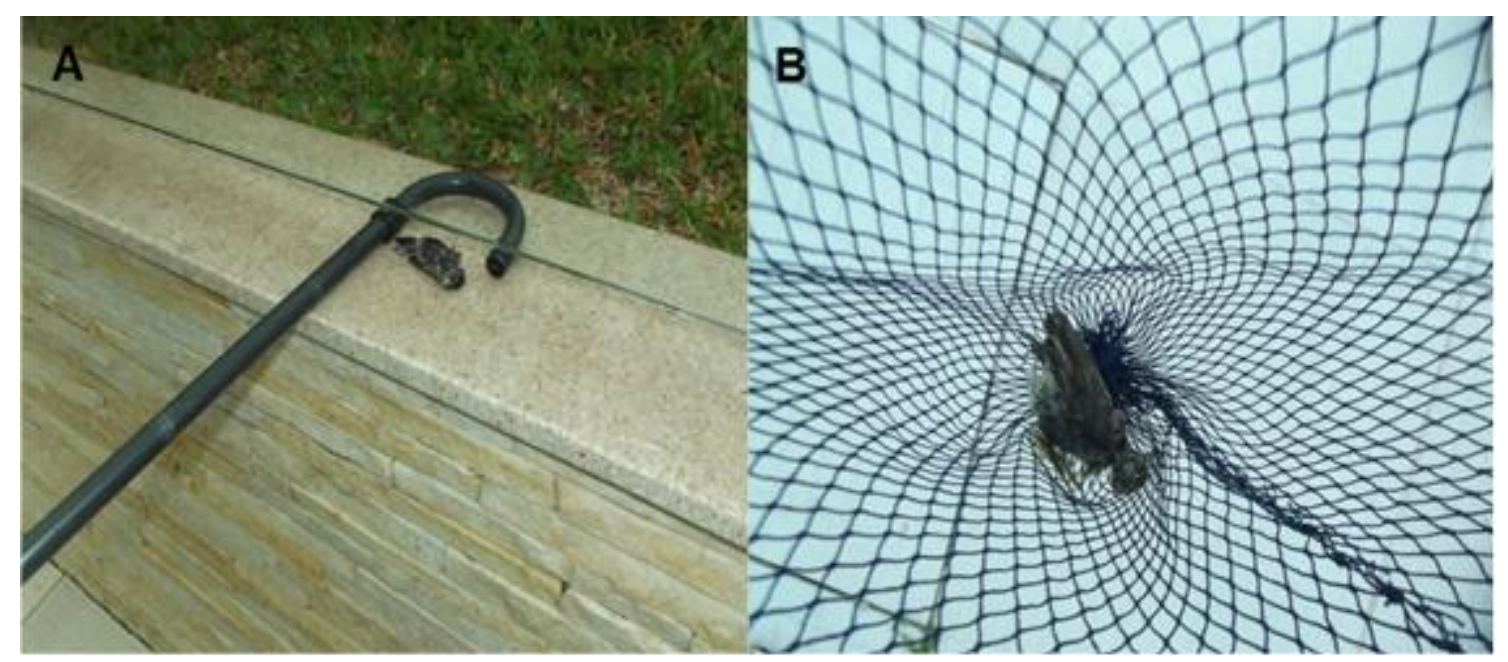

Fonte: Autores.

As carcaças das aves eram colocadas sobre uma folha A4 de cor branca, com uma régua de $30 \mathrm{~cm}$ para servir de escala, e então fotografadas individualmente evidenciando as estruturas de bico, asas, cauda, pés, ambas as asas abertas, e envergadura.

Cada indivíduo amostrado recebeu um código no momento da coleta, assim como realizou-se o registro em ficha de campo, com data, coordenada geográfica, observações e coletor responsável. As carcaças foram acondicionadas em sacos 
plásticos individuais, transportadas em uma caixa de isopor e, posteriormente, congeladas, e encaminhadas para o Museu de Zoologia Prof ${ }^{a}$ Morgana Cirimbelli Gaidzinski (UNESC) onde foram depositadas, identificadas e catalogadas.

As carcaças passaram por biometria seguindo os conceitos adotados por Bub (1991), onde considerou-se o comprimento do bico (na base do bico no crânio até a ponta do bico em linha reta), altura do bico (da parte inferior até a base da parte superior do bico), largura do bico (o diâmetro na parte próxima da cabeça), comprimento da cauda (da ponte do pigstilo até sua extremidade), comprimento da asa (com a asa da ave fechada, mede-se desde a primeira articulação da asa até a ponta da maior pena primária, estendendo-se as primárias paralelamente à régua), comprimento do tarso (da inserção do tarso-metatarso até o início dos artelhos), comprimento total (da ponta do bico até a extremidade da cauda), medida da envergadura (da extremidade de uma asa a outra). Além das medidas citadas, as aves foram pesadas utilizando a balança de precisão, a unidade de medida foi em gramas, ainda com o auxílio de biólogos do Museu de Zoologia Prof ${ }^{a}$ Morgana Cirimbelli Gaidzinski (UNESC) determinou-se o sexo dos indivíduos, faixa etária e a identificação em nível genérico ou específico.

A equipe de execução possui autorização da Comissão de Ética em Uso de Animais (CEUA/UNESC) de número 046/2013 e também do Sistema de Autorização e Informação em Biodiversidade (SISBIO) que concedeu autorização de número 39331, para coleta e transporte das carcaças das aves pós-colisões.

Além das aves amostradas, foram medidas as extensões dos muros (altura $\mathrm{x}$ largura) das residências amostradas para avaliar se há influência entre o tamanho do muro e o número de acidentes.

\subsection{Análise estatística}

Os dados coletados foram armazenados em planilha de Excel, que serviu como banco de dados, para facilitar a análise e comparação. Acrescentou-se ainda ao banco de dados informações de coleta e biometria das carcaças devidamente identificadas por códigos.

Realizaram-se cálculos de médias e desvio padrão dos dados biométricos de cada espécie coletada. Assim como foi realizado os cálculos de médias das extensões 
dos muros de vidro, sendo estes dados confrontados com o número de aves colididas em cada residência amostrada. Também foi realizada análise gráfica de ocorrência das colisões por mês de amostragem.

\section{RESULTADOS}

No decorrer de período de estudo foram amostradas, entre coletas e registros fotográfico das aves, um total de 110 carcaças decorrentes das colisões em estruturas de vidro, distribuídas em 12 espécies e 10 famílias, sendo 21 indivíduos não identificados (Tabela 1).

Tabela 1 - Lista taxonômica das aves colididas em muros de vidro amostradas durante a pesquisa no município de Balneário Rincão, Santa Catarina.

\begin{tabular}{|c|c|c|}
\hline Família/Espécie & Nome popular & $\overline{\mathrm{N}^{0} \text { de indivíduos }}$ \\
\hline \multicolumn{3}{|l|}{ COLUMBIDAE Leach, 1820} \\
\hline Columbina passerina (Linnaeus, 1758) & Rolinha-cinzenta & 4 \\
\hline \multicolumn{3}{|l|}{ TROCHILINAE Vigors, 1825} \\
\hline Eupetomena macroura (Gmelin, 1788) & Beija-flor & 2 \\
\hline \multicolumn{3}{|l|}{ TYRANNAIDAE Vigors, 1825} \\
\hline Elaenia spectabilis Pelzeln, 1868 & Guaracava-grande & 2 \\
\hline Tyrannus melancholicus Vieillot, 1819 & Suiriri & 2 \\
\hline \multicolumn{3}{|l|}{ HIRUNDINIDAE Rafinesque, 1815} \\
\hline Pygochelidon cyanoleuca (Vieillot, 1817) & Andorinha-pequena-de-casa & 1 \\
\hline \multicolumn{3}{|l|}{ TROGLODYTIDAE Swainson, 1831} \\
\hline Troglodytes musculusNaumann, 1823 & Corruíra & 1 \\
\hline \multicolumn{3}{|l|}{ TURDIDAE Rafinesque, 1815} \\
\hline Turdus amaurochalinusCabanis, 1850 & Sabia-poca & 2 \\
\hline \multicolumn{3}{|l|}{ PARULIDAE Wetmore, Friedmann, Lincoln, } \\
\hline \multicolumn{3}{|l|}{ Miller, Peters, Van Rossem, Van Tyne \& } \\
\hline \multicolumn{3}{|l|}{ Zimmer 1947} \\
\hline Geothlypis aequinoctialis (Gmelin, 1789) & Pia-cobra & 1 \\
\hline \multicolumn{3}{|l|}{ THRAUPIDAE Cabanis, 1847} \\
\hline Sicalis flaveola (Linnaeus, 1766) & Canarinho & 22 \\
\hline Tangara sayaca (Linnaeus, 1766) & Sanhaçu-cinzento & 3 \\
\hline ESTRILDIDAE Bonaparte, 1850 & & \\
\hline
\end{tabular}


Revista Tecnologia e Ambiente, v. 21, n.1, 2015, Criciúma, Santa Catarina. ISSN: 1413-8131 (versão impressa) ISSN: 2358-9426 (versão eletrônica)

Estrilda astrild (Linnaeus, 1758)

Bico-de-lacre

PASSERIDAE Rafinesque, 1815

Passer domesticus (Linnaeus, 1758)

Pardal

22

Não identificado

21

Fonte: Autores.

A espécie com maior registro de colisão foi Estrilda astrild (Linnaeus, 1758), popularmente conhecido como bico-de-lacre, com 27 carcaças amostrados, sendo que 24 indivíduos foram registrados em uma mesma residência no mês de julho de 2013. Outras duas espécies frequentemente encontradas colididas foram o pardal e o canarinho, totalizando 22 carcaças cada.

Devido ao grau de decomposição e em algumas vezes a impossibilidade da coleta das carcaças, somente 32 dos 110 indivíduos foram coletados e tiveram a biometria, sexagem e determinação da idade realizada (Tabela 2).

Tabela 2 - Lista das aves colididas em muros de vidro coletadas durante a pesquisa no município de Balneário Rincão, Santa Catarina, com os dados de biometria, sexagem e idade. 


\begin{tabular}{|c|c|c|c|c|c|c|c|c|c|c|c|c|c|c|c|}
\hline \multirow[b]{2}{*}{ Espécie } & \multirow[b]{2}{*}{ CB (cm) } & \multirow[b]{2}{*}{$\mathrm{AB}(\mathbf{c m})$} & \multirow[b]{2}{*}{ LB (cm) } & \multirow[b]{2}{*}{$\mathrm{CC}(\mathrm{cm})$} & \multirow[b]{2}{*}{$\mathrm{CA}(\mathbf{c m})$} & \multirow[b]{2}{*}{ CT (cm) } & \multirow[b]{2}{*}{ CTO (cm) } & \multirow[b]{2}{*}{ ME (cm) } & \multirow[b]{2}{*}{$\mathbf{P}(\mathbf{g})$} & \multicolumn{3}{|c|}{ Sexo } & \multicolumn{3}{|c|}{ Faixa etária } \\
\hline & & & & & & & & & & $\mathbf{F}$ & $\mathbf{M}$ & IN & $\mathbf{A}$ & $\mathbf{J}$ & IN \\
\hline Elaenia spectabilisPelzeln, 1868 & $1,100 \pm 0$ & $0,4 \pm 0$ & $\begin{array}{c}0,550 \pm \\
0,050\end{array}$ & $\begin{array}{c}5,950 \pm \\
0,050\end{array}$ & $\begin{array}{c}9,100 \pm \\
1,400\end{array}$ & $\begin{array}{c}5,900 \pm \\
4,000\end{array}$ & $\begin{array}{c}8,00 \pm \\
6,00\end{array}$ & $\begin{array}{c}14,55 \pm \\
0,45\end{array}$ & $\begin{array}{c}18,08 \pm \\
2,86\end{array}$ & 0 & 0 & 2 & 0 & 0 & 2 \\
\hline Tyrannus melancholicus Vieillot, 1819 & $2,00 \pm 0$ & $0,40 \pm 0$ & $0,60 \pm 0$ & $7,9 \pm 0$ & $13,90 \pm 0$ & $3,20 \pm 0$ & $20,51 \pm 0$ & $31,00 \pm 0$ & $33,72 \pm 0$ & 0 & 0 & 1 & 0 & 0 & 1 \\
\hline Pygochelidon cyanoleuca (Vieillot, 1817) & $0,80 \pm 0$ & $0,20 \pm 0$ & $0,50 \pm 0$ & $4,00 \pm 0$ & $9,70 \pm 0$ & $1,80 \pm 0$ & $10,70 \pm 0$ & $25,00 \pm 0$ & $8,42 \pm 0$ & 0 & 0 & 1 & 0 & 1 & 0 \\
\hline Troglodytes musculusNaumann, 1823 & $1,70 \pm 0$ & $0,50 \pm 0$ & $0,50 \pm 0$ & $3,50 \pm 0$ & $5,0 \pm 0$ & $1,40 \pm 0$ & $10,50 \pm 0$ & $16,50 \pm 0$ & $11,68 \pm 0$ & 0 & 0 & 1 & 0 & 0 & 1 \\
\hline Turdus amaurochalinusCabanis, 1850 & $2,30 \pm 0$ & $0,70 \pm 0$ & $0,50 \pm 0$ & $9,50 \pm 0$ & $14,50 \pm 0$ & $3,20 \pm 0$ & $23,00 \pm 0$ & $34,00 \pm$ & $60,53 \pm 0$ & 0 & 0 & 1 & 0 & 0 & 1 \\
\hline Geothlypis aequinoctialis (Gmelin, 1789) & $1,20 \pm 0$ & $0,60 \pm 0$ & $0,20 \pm 0$ & $5,00 \pm 0$ & $5,50 \pm 0$ & $2,10 \pm 0$ & $12,50 \pm 0$ & $16,0 \pm 0$ & $12,23 \pm 0$ & 0 & 1 & 0 & 0 & 0 & 1 \\
\hline Sicalis flaveola (Linnaeus, 1766) & $\begin{array}{c}0,88 \pm \\
0,13\end{array}$ & $\begin{array}{c}0,61 \pm \\
0,10\end{array}$ & $0,55 \pm 0,06$ & $5,21 \pm 0,62$ & $8,78 \pm 1,01$ & $1,83 \pm 0,17$ & $\begin{array}{c}13,46 \pm \\
0,97\end{array}$ & $\begin{array}{c}21,86 \pm \\
0,52\end{array}$ & $\begin{array}{c}17,18 \pm \\
0,83\end{array}$ & 7 & 5 & 1 & 0 & 1 & 12 \\
\hline Tangara sayaca (Linnaeus, 1766) & $\begin{array}{c}1,56 \pm \\
0,09\end{array}$ & $\begin{array}{c}0,76 \pm \\
0,04\end{array}$ & $0,86 \pm 0,09$ & $6,16 \pm 0,12$ & $\begin{array}{c}12,10 \pm \\
0,88\end{array}$ & $2,36 \pm 0,20$ & $\begin{array}{c}17,83 \pm \\
0,62\end{array}$ & $\begin{array}{c}29,50 \pm \\
0,40\end{array}$ & $\begin{array}{c}25,05 \pm \\
17,73\end{array}$ & 0 & 0 & 3 & 0 & 0 & 3 \\
\hline Estrilda astrild (Linnaeus, 1758) & $0,70 \pm 0$ & $0,50 \pm 0$ & $0,40 \pm 0$ & $5,40 \pm 0$ & $6,80 \pm 0$ & $1,50 \pm 0$ & $11,0 \pm 0$ & $14,0 \pm 0$ & $5,93 \pm 0$ & 0 & 1 & 1 & 1 & 0 & 1 \\
\hline Passer domesticus (Linnaeus, 1758) & $\begin{array}{c}1,17 \pm \\
0,15\end{array}$ & $\begin{array}{c}0,74 \pm \\
0,14\end{array}$ & $0,65 \pm 0,05$ & $5,71 \pm 0,60$ & $\begin{array}{c}10,08 \pm \\
0,60\end{array}$ & $1,92 \pm 0,21$ & $\begin{array}{c}15,52 \pm \\
0,82\end{array}$ & $\begin{array}{c}23,80 \pm \\
0,67\end{array}$ & $\begin{array}{c}26,00 \pm \\
2,14\end{array}$ & 4 & 3 & 1 & 0 & 0 & 8 \\
\hline
\end{tabular}

Legenda: $\mathrm{CB}$ - comprimento do bico; $\mathrm{AB}$ - altura do bico; $\mathrm{LB}$ - largura do bico; $\mathrm{CC}$ - comprimento da cauda; $\mathrm{CA}$ - comprimento da asa; CT - comprimento do tarso; CTO - comprimento total; ME - medida da envergadura; P - peso; F - fêmea; M - macho; IN -

indeterminado; $\mathrm{A}$ - adulto; $\mathrm{J}$ - jovem 
Ao longo do ano de estudo houve pouca variação no número de carcaças de aves amostradas mensalmente, variando entre duas e 12 indivíduos, com exceção do mês de julho onde foram registradas 34 indivíduos colididos (Figura 3).

Figura 3 - Registro das aves colididas em muros de vidro amostradas por coleta ou registro fotográfico durante o período de estudo no Balneário Rincão, distribuídas mensalmente.

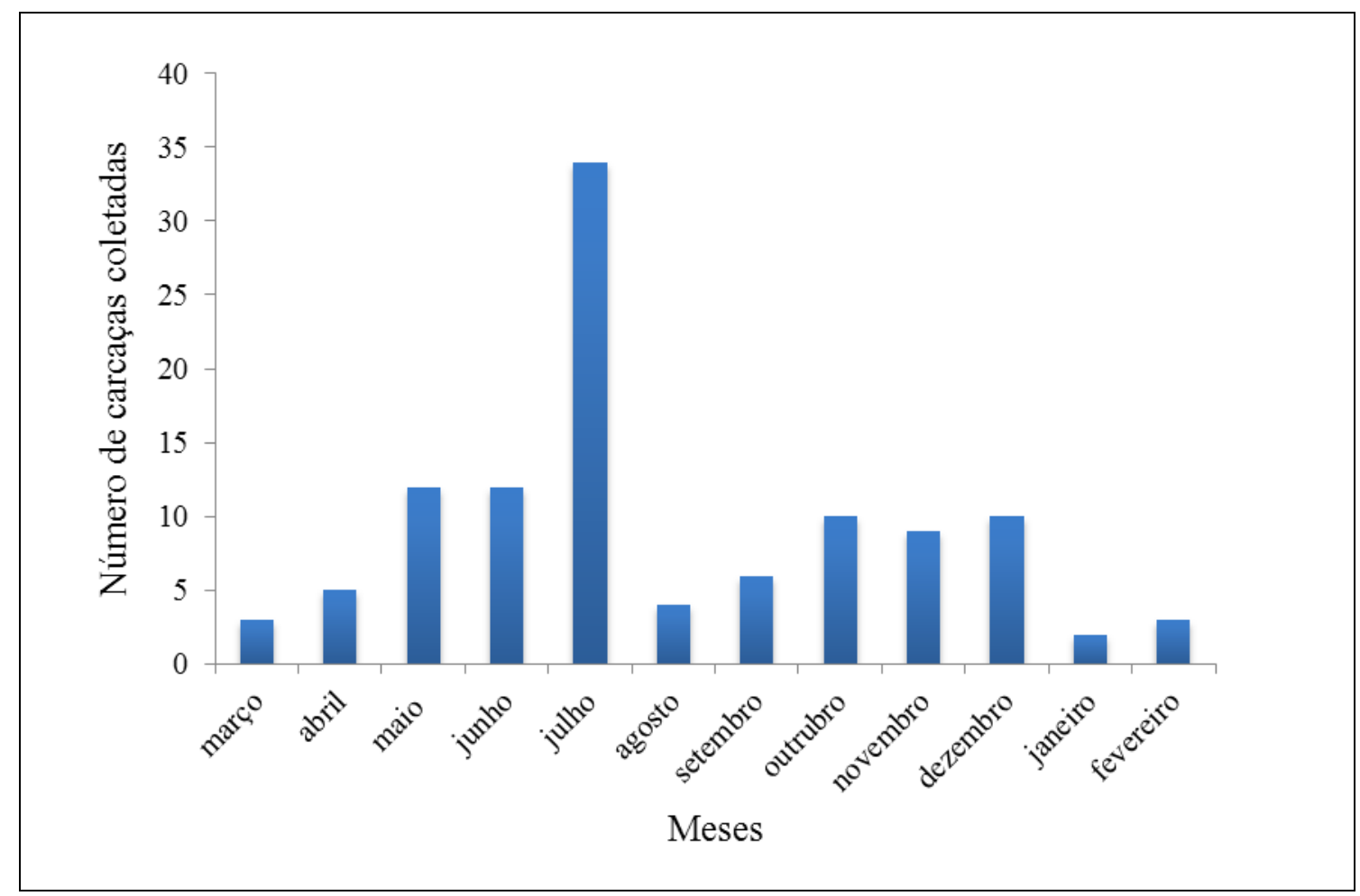

Buscando caracterizar as estruturas transparentes das residências amostradas, através da metragem, verificou-se que em média as vidraças possuem $22 \mathrm{~m}^{2}$ de área, sendo que o menor muro media $9 \mathrm{~m}^{2}$, e o maior $155 \mathrm{~m}^{2}$. A figura 4 apresenta os números de colisões e seus respectivos tamanhos, analisando os dados, o maior número de aves que colidiram em um mesmo ponto, o mesmo apresenta a maior área quadrada com um valor de $155 \mathrm{~m}^{2}$, o segundo ponto que mais ocorreram às colisões apresenta uma área de $31 \mathrm{~m}^{2} \mathrm{e}$ o terceiro ponto possui uma área de $10 \mathrm{~m}^{2}$, sendo que muros com áreas de $48 \mathrm{~m}^{2}, 43 \mathrm{~m}^{2}$ e $40 \mathrm{~m}^{2}$ não ocorreram colisões. Contudo, em alguns pontos amostrados, os números de colisões eram baixos e os registros não ocorriam devido à residência possuir pessoas responsáveis pela limpeza que fazia o descarte das aves que colidiam. 
Figura 4 - Registro das aves colididas em muros de vidro amostradas no município de Balneário Rincão, Santa Catarina, considerando a área das estruturas dos muros.

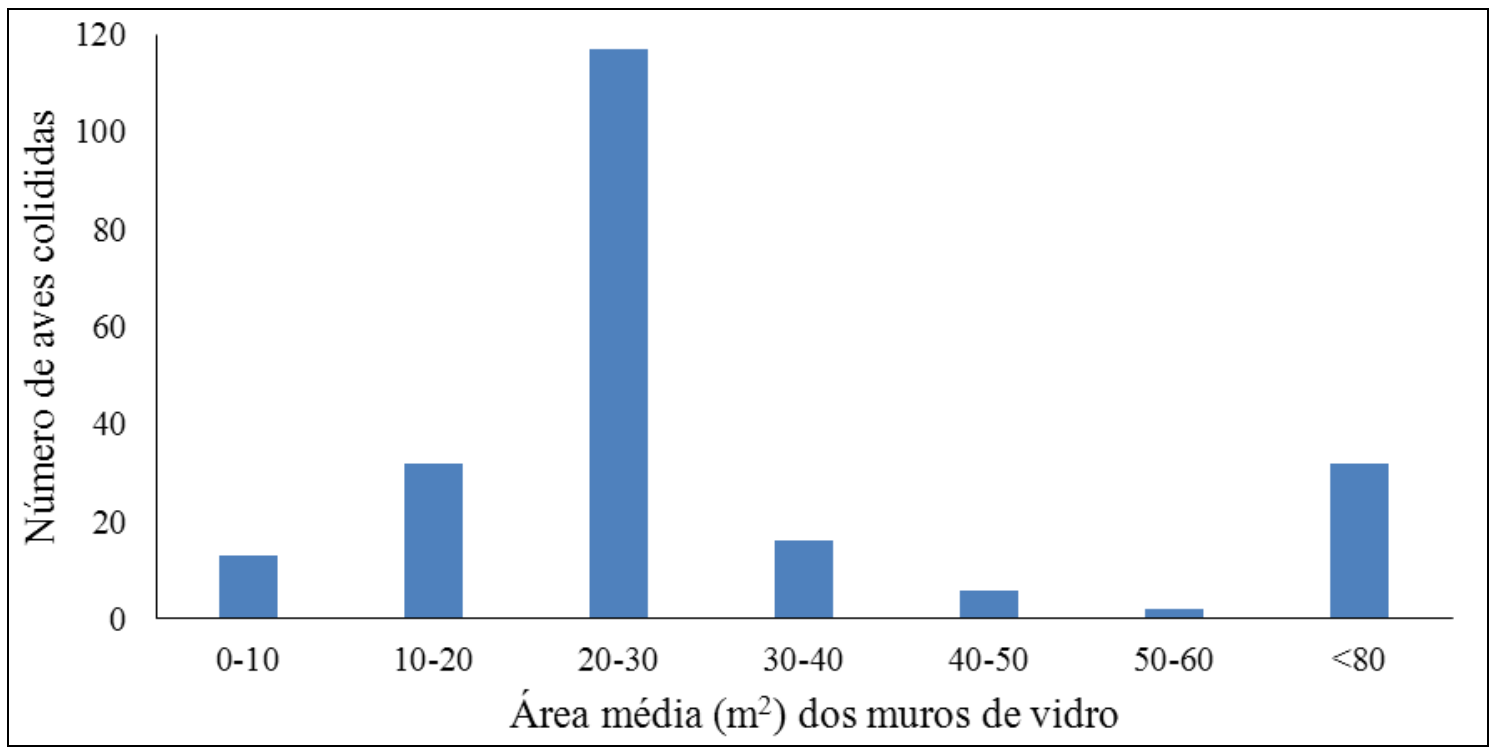

A presença de vegetação nessas áreas litorâneas é escassa, apresentando em maior proporção a vegetação rasteira e arbustos. A análise da vegetação realizada em torno dos pontos amostrados mostra predomínio de gramínea e arbustos com altura entre $10 \mathrm{~cm}$ e $1 \mathrm{~m}$ de altura, e árvores. Observou-se que onde há presença de árvores, ou seja, vegetação com mais de um metro de altura, os acidentes foram mais frequentes. Isso se deve possivelmente a maior circulação de aves nestes locais, visto que esses ambientes oferecem abrigo e alimento. Outro fato importante foi a proximidade de algumas árvores dos muros, provocando a reflexão quase que perfeita, influenciando na frequência de colisões.

\section{DISCUSSÃO}

Os dados obtidos neste estudo são pioneiros para o cenário nacional, sendo encontrado pouco material publicados para comparação (FERRARI et al., 2012; SANTOS et al., 2012). Um estudo realizada na Universidade do Vale do Paraíba indica a ocorrência frequente de colisões de aves sobre a passarela envidraçada que liga alguns prédios da instituição, através de observação e registro verbal de funcionários da universidade (SANTOS et al. 2012). 
No estudo realizado por Barros (2010), o número de aves que colidiram em vidraças ao longo de três meses, em Toronto no Canadá, foi de 1000 indivíduos. Usando esse dado para realizar a comparação com a amostra do presente trabalho, podemos dizer que na área de estudo colidem 0,3 indivíduos/dia, já em Toronto colidem 11,1 indivíduos/dia. Entretanto, considerando à extensão e o índice de estruturas transparentes existentes que diferem-se significativamente entre os locais, a análise se mostra parcial.

As espécies de aves coletadas colididas neste estudo são todas de ocorrência no Brasil, com evidencias de reprodução no país (CBRO, 2014). São aves presentes em várias regiões, adaptadas e comumente encontradas em habitats urbanos e litorâneos (WIKIAVES, 2014).

Os resultados obtidos neste estudo não apontam uma relação entre o sexo ou idade das aves e um aumento no número de colisões. Os registros mensais de carcaças amostradas também não indicam sazonalidade na colisão das aves, apesar dos meses de verão o número de coletas ter diminuído, fato este possivelmente influenciado pelo aumento de veranistas que poderiam estar coletando as carcaças de seus pátios, contando também com a presença maior de predadores das aves, como cachorros e gatos. O valor discrepante no mês de julho foi alavancado pelo fato da amostragem de 24 bicos-de-lacre, acontecimento esse justificado por essa espécie andar em bandos.

Segundo Klem (1989), não ocorre influência de sexo, idade ou tamanho das áreas de vidro sobre a vulnerabilidade à colisão. Ainda segundo este autor, não há nenhuma estação, hora do dia, e nem qualquer condição de tempo durante o qual as aves possam escapar do perigo que são as vidraças, pois elas não conseguem reconhecer os painéis de vidro transparente ou reflexivo como barreiras.

Como citado anteriormente, o Balneário Rincão foi emancipado recentemente, e tem-se observado uma expansão no território, paralelamente a isto os muros de vidro estão cada vez mais frequentes na região. Ao final do presente estudo, foram identificadas 32 novas residências na rota da área de amostragem que optaram pelo uso de estruturas de vidro.

Levando em consideração o aumento contínuo das construções com muros de vidro, uma forma de combater a mortalidade da avifauna por colisões, seria sensibilizando a população sobre o assunto juntamente com os órgãos governamentais 
do município. Materiais educativos deveriam ser distribuídos e antes da liberação para construção, os proprietários deveriam estar informados sobre o assunto.

Para as construções com estruturas de vidro existem técnicas para evitar as colisões da avifauna. De acordo com Barros (2010) cobrir as mesmas com uma rede, que impediria os mesmos de colidir com o vidro. Contudo, essa solução só é aplicável em janelas de tamanho pequeno a médio. Também é possível evitá-las ao cobrir as parcialmente as janelas com cortinas opacas ou translúcidas, ou qualquer elemento, de diferentes formas e tamanhos, desde que separados, no máximo por $5 \mathrm{~cm}$ ou $10 \mathrm{~cm}$.

Outro método para evitar colisões é um filme, chamado Collidscape, opaco pelo lado de fora, capaz de alertar os pássaros do perigo, mas que parece transparente a quem vê de dentro, não prejudicando a vista da paisagem externa. Existe ainda um produto denominado Ornilux, que é uma espécie de vidro tratado com padrões de revestimento ultravioleta, que os pássaros enxergam e, por isso, evitam. É baseado em teias de aranha, que contém uma seda refletora de raios ultravioleta, para evitar que os pássaros passem por elas e as destruam (BARROS, 2010).

Ainda segundo o mesmo autor, há também o BirdChase, que emite ultrassom, em intervalos específicos de frequência, inaudíveis ao ser humano, e que impede os pássaros de entrar em uma área ao redor de $1.800 \mathrm{~m}^{2}$. E outra tecnologia desenvolvida nesse sentido, é o Bye-Bye Birdie, um repelente de pássaros baseado nos princípios científicos do campo geomagnético - essencial aos pássaros para determinar sua direção e direcionamento. Ele emite um campo magnético que cobre um raio de 21 metros, que perturba o campo geomagnético, que confunde os pássaros e os mantém afastados da área perturbada.

A conscientização da população é indispensável referente as colisões, o aprofundamento na parte de divulgação deve caminhar junto com a pesquisa, e sendo continuamente melhorada para que esse problema seja amenizado na região, assim como também nos outros países.

\section{AGRADECIMENTOS}

Os autores agradecem à Universidade do Extremo Sul Catarinense (UNESC) e a PróReitora de Pós-Graduação, Pesquisa e Extensão pelo financiamento e bolsa de extensão concedida aos autores. Também, estendemos nossos agradecimentos ao Museu de 
Zoologia Prof ${ }^{a}$ Morgana Cirimbelli Gaidzinski (UNESC), pelo auxilio e parceria durante o decorrer do projeto e aos Professores Dr. Márcio Sônego que nos amparou na descrição do clima ao Dr. Daniel Klem Jr., no envio de artigo para subsidiar nossos resultados, ao Professor Me. Hugo Schwalm e ao bolsista Henrique Mattos que nos auxiliaram na confecção do mapa georreferenciado e utilização do GPS.

\section{REFERÊNCIAS}

BARROS, L. C. Morte de pássaros por colisão com vidraças. Revista Ciências do Ambiente On-line, São Paulo, v. 6, n. 3, p.58-61. 2010. Disponível em: $<$ http://sistemas.ib.unicamp.br/be310/nova/index.php/be310/article/view/265>. Acesso em: 01 abr. 2010.

BUB, H. Bird trapping and bird banding: a handbook for trapping methods all over the world. Cornell University Press, Ithaca, New York. 1991.

COMITÊ BRASILEIRO DE REGISTROS ORNITOLÓGICOS. Listas das aves do Brasil. 2014. Disponível em <http://www.cbro.org.br>. Acesso em: 13 out. 2014.

FERRARI, L. D. R.; FAZION, F.; FRANCO, L.; BOSSI, N.; LEODORO, L.; MARTINS, C.; PAULA, H.; PAULA, S. Colisão de aves em vidraças no Setor Litoral da Universidade Federal do Paraná. Publicação de resumo do artigo. In: IV Seminário de Integração dos Servidores Técnico-Administrativos em Educação. 2012, Matinhos/PR. Caderno de Resumos do IV Seminário de Integração dos Servidores Técnico-Administrativos em Educação. Matinhos/PR: Universidade Federal do Paraná Setor Litoral e CEM, 2012. v. 01. p. 24-24.

HICKMAN-JUNIOR, C. P.; ROBERTS, L. S.; LARSON, A. Princípios integrados de zoologia. Rio de Janeiro: Guanabara Koogan S.A, 2004.

HORN, D. J.; COLLINS, K. A. Bird window collisions and factors influencing their frequency at Millikin University in Decatur Illinois. Disponível em: <http://www.birdsandbuildings.org/docs/MillikenUResearch.pdf>. Acesso em: 23 jul. 2012.

INSTITUTO BRASILEIRO DE GEOGRAFIA E ESTATÍSTICA (IBGE). Censo Demográfico 2010: Resultados da Amostra - Características da População. 2010. Disponível em: <http://www.balneariorincao.sc.gov.br/municipio/index/codMapaItem/4334\#.Ux9dL_ld XKo>. Acesso em: 19 mar. 2014.

KLEM-JUNIOR, D. Bird window collisions. The Wilson bulletin, Pennsylvania, v. 101, n. 4, p. 606-620, 1989. 
MARINI, A. M; GARCIA, I. F. Conservação de aves no Brasil. Brasilía:

Megadiversidade. 2005. Disponível em:

<http://www.conservation.org.br/publicacoes/files/14_Marini_Garcia.pdf > Acesso em: 19 de março, 2014.

MONTANO, P. F.; BASTOS, H. B. A indústria de vidro plano: conjuntura atual e perspectivas. BNDS Setorial, v. 38, p. 265-290, 2013.

PRIMACK, R. B.; RODRIGUES, E. Biologia da conservação. Londrina: Midiograf, 2001.

SAN FRANCISCO PLANNING DEPARTMENT. Standards for bird safe buildings. v. 7, p. 41, 2011.

SANTOS, T. M.; CUNHA, J. G.; MONTEIRO, A. R. Utilização de silhuetas para minimizar e/ou evitar, colisão de aves sobre as vidraças na passarela do Instituto de Pesquisa e Desenvolvimento - IP\&D em São José dos Campos, SP/Brasil. 2011. In: XIV Encontro Latino Americano de Iniciação Científica e X Encontro Latino Americano de Pós-Graduação, Paraíba, 2010. Versão eletrônica. Disponível em: <http://www.inicepg.univap.br/cd/INIC_2010/anais/arquivos/RE_0190_0782_01.pdf>. Acesso em 23 jun. 2012.

TERRA, G. M.; CONSTANTE, M. L. V. Asas da liberdade: aves unindo hemisférios. Universidade Luterana do Brasil, Torres/Mostardas, 2005. Disponível em: <http://www.mostardas.tur.br/portal/html/uploads/turismo/artigos/graziela-marisa.pdf>. Acesso em: 23 jun. 2012.

VALENTE, R. M. de; SILVA, J. M. C. da; STRAUBE, F. C.; NASCIMENTO, J. L. X. do. (Org.) Conservação de aves migratórias neárticas no Brasil. Belém: Conservação Internacional, 2011. Disponível em: $<$ http://ppbio.inpa.gov.br/sites/default/files/Livro\%20Aves\%20migratorias\%20nearticas $\% 20$ no\%20brasil\%20-\%20Conservation\%20International.pdf >. Acesso em: 13 out. 2014.

WIKIAVES. Enciclopédia de aves do Brasil. Disponível em: <http://www.wikiaves.com.br/>. Acesso em: 24 nov. 2014. 